Original Article

\title{
EFFECT OF GRANULE SIZE, COMPACTION PRESSURE AND CONCENTRATION OF MALVA VERTICILLATA MUCILAGE ON THE IN VITRO PROPERTIES OF TABLETS
}

\author{
PATRICK CHERUIYOT KORIR ${ }^{*}$, ALI MOHAMED SALIM ${ }^{2}$, JOSIAH OCHIENG ODALO ${ }^{1}$, WALYAMBILLAH WAUDO ${ }^{2}$, \\ LEONARD MWANGI GITU2
}

${ }^{1}$ Department of Pure and Applied Sciences, Technical University of Mombasa, Mombasa, Kenya, ${ }^{2}$ Department of Chemistry, Jomo Kenyatta University of Agriculture and Technology, Nairobi, Kenya

Email: korircheruiyotpatrick@tum.ac.ke

Received: 12 Apr 2017 Revised and Accepted: 20 Apr 2018

ABSTRACT

Objective: To evaluate the effect of binder concentration, granule size and distance between punches on mechanical strength and drug release properties of tablets containing Malva verticillata mucilage (MVM) as a binder.

Methods: Paracetamol and lactose were converted into wet coherent masses by a liquid solution containing 1-3\% w/w MVM as a binder. Granules containing $2 \% \mathrm{w} / \mathrm{w}$ binder was used to investigate the effect of granule size and distance between punches. Compressed tablets were evaluated for crushing strength, disintegration time and in vitro drug release using pharmacopeial methods.

Results: Granules containing MVM were found to be free-flowing and compatible with paracetamol. Mechanical strength and drug release properties of mucilage tablets significantly correlated with the amount of MVM binder. Tablet crushing strength was $3.54-7.12 \mathrm{~kg} / \mathrm{cm}^{2}$ while disintegration time 7.13-16.67 min. Compression pressure and granule size had no significant effects on drug release properties of mucilage tablets. Crushing strength of mucilage tablets were higher and significantly different $\left(\mathrm{t}_{(26)}=7.9631, \mathrm{p}<0.05\right)$ from acacia tablets in the tested variables. The cumulative drug release rate of mucilage tablets was also lower than that of acacia tablets in tested concentrations.

Conclusion: Properties of tablets containing 2.5\% w/w MVM matched the prescribed pharmaceutical limits and hence $M$. verticillata root mucilage has a great potential to become a new source of tablet binder.

Keywords: Malva verticillata, Mucilage, Acacia gum, Binder, Dissolution, Paracetamol

(C) 2018 The Authors. Published by Innovare Academic Sciences Pvt Ltd. This is an open access article under the CC BY license (http://creativecommons.org/licenses/by/4.0/) DOI: http://dx.doi.org/10.22159/ijpps.2018v10i6.25553

\section{INTRODUCTION}

Tablets remain one of the most important dosage forms of presenting pharmacologically active ingredients. Common problems encountered during manufacturing and use of tablets include incompatibility, poor flow, mechanical strength and poor drug release rates $[1,2]$. Incompatibility due to chemical and intergranulate interactions compromises stability, efficacious and viability of drug content. Also, the type and amount of binder, granules size and compression pressure influence mechanical strength and bioavailability of the formulated tablet. This calls for optimization of stated variables in order to strike a balance between the properties of compressed tablets.

Binders are included in a tablet formulation to improve granule flow, promote cohesiveness and strengthen intra-granular bonds. High concentration of binder leads to the formation of stronger tablets but with poor drug release rates [3]. The choice of a binder depends on compatibility with other ingredients, ability to improve mechanical strength and release of the drug to achieve its intended purposes $[1,4$, 5]. Properties of aggregates and tablets vary with granule size [6]. It was earlier reported that decrease in granule size before compression corresponds to an increase in tablet strength [7], however, it has since been established that there is no correlation $[8,9]$. The magnitude of compression force affects deformation of granules which subsequently alter tablet hardness and disintegration time with or without significant effect on dissolution rate [10-12].

Mucilage obtained from a number of plant species have been evaluated as tablet binders, thickening agents and as the polymer in sustained release tablets [10, 13-15]. However, these efforts have yielded few potential tablet binders with some being reported to demonstrate inferior performance as compared to the commercially available binders [15].
Malva verticillata L. (Cluster mallow, Malvaceae) is often used as a vegetable and as a herb in traditional medicine. The plant grows as a herb with alternate leaves that have five to seven lobes. It is an annual plant that grows in well-drained moist soil with moderate fertility into variable size ranging from low lying to $1.7 \mathrm{~m}$ tall [16, 17]. The roots of $M$. verticillata when peeled or soaked in water releases a sticky slippery fluid which can be exploited as a tablet binder. The aim of this study was to optimize the potential of MVM as a tablet binder by assessing the effect of binder concentration, granule size and distance between punches on the in vitro properties of the formulated tablets.

\section{MATERIALS AND METHODS}

Paracetamol IP, lactose $\mathrm{BP}$, acacia gum BP, talc and magnesium stearate were sourced from the pharmaceutical manufacturing company. Other reagents used were of analytical grade. $M$. verticillata roots were collected from Eastlands, Nairobi CountyKenya, after authentication by a taxonomist. Sample specimen was preserved at The University of Nairobi herbarium, voucher number, PCK2015/01.

\section{Extraction and purification of mucilage}

Air dried root bark of M. verticillata was grounded into 250-500 $\mu \mathrm{m}$ size particles. These were then pre-treated with $95 \%$ ethanol in a boiling-water bath for $1 \mathrm{~h}$ to remove pigments and organic compounds. Distilled water containing $1 \%$ sodium metasulphite was added to the pre-treated root bark at the ratio of $20: 1(\mathrm{ml} / \mathrm{g})$ and stirred regularly at $50{ }^{\circ} \mathrm{C}$ for $3 \mathrm{~h}$ to arrest oxidation, microbial growth and enzymatic activity. The mixture was strained through a fourfold muslin cloth and centrifuged at $3000 \mathrm{rpm}$ for $10 \mathrm{~min}$ to remove fine insoluble fibre. The supernatant was deprotonated with a mixture of chloroform and n-butanol $(4: 1 \mathrm{v} / \mathrm{v})$ in a boiling water bath for $10 \mathrm{~min}$ to remove soluble proteins. The resulting filtrate 
was then mixed with $95 \%$ ethanol at equal volumes to dissolve the mucilage. The obtained mucilage was then dried at $45^{\circ} \mathrm{C}$ in an oven dryer, grounded and passed through British standard sieve (BSS) no. $60(250 \mu \mathrm{m})$ before storing in airtight bags at room temperature.

\section{Preparation of granules}

The model drug (paracetamol) and diluent (lactose) were homogenously dry-mixed in a pestle and mortar. This blend was converted into a wet coherent mass by adding $15 \mathrm{ml}$ of a liquid suspension containing 1.0 to $3.0 \% \mathrm{w} / \mathrm{w}$ of tablet binder (table 1). The wet mass was forced through a BSS no.18 $(1000 \mu \mathrm{m})$, dried in a hot air oven at $50{ }^{\circ} \mathrm{C}$ to obtain granules with a moisture content below $2.9 \% \mathrm{w} / \mathrm{w}$. These were then mixed with $1 \%$ talc as an internal lubricant and stored in airtight bags. The lubricant was added after granulation as wet lubricants interfere with the disintegration of tablets. In this study, disintegrants were not included in the formulations.

Table 1: Formulation of tablets with different amounts of binder

\begin{tabular}{lllll}
\hline \% w/w of binder & \multicolumn{2}{l}{ Tablet ingredients } & & \\
\cline { 2 - 5 } per tablet & Binder (mg) & Paracetamol (mg) model drug & Lactose (mg) diluents & Talc (mg) lubricant \\
\hline 1.0 & 3.0 & 250 & 44.0 & 3.0 \\
1.5 & 4.5 & 250 & 42.5 & 3.0 \\
2.0 & 6.0 & 250 & 41.0 & 3.0 \\
2.5 & 7.5 & 250 & 39.5 & 3.0 \\
3.0 & 9.0 & 250 & 38.0 & 300 \\
\hline
\end{tabular}

\section{Compression of granules}

Granules containing 1.0 to $3.0 \% \mathrm{w} / \mathrm{w}$ binder were passed through BSS no. $25(710 \mu \mathrm{m})$ and compacted into $300 \mathrm{mg}$ circular tablet by a single punch press and stored over silica gel, to allow for elastic recovery. Granules containing $2 \% \mathrm{w} / \mathrm{w}$ binder were divided into two portions. The first portion was shaken through a nest of sieves to give three fractions viz. 149-250 $\mu \mathrm{m}, 250-500 \mu \mathrm{m}$ and 500-707 $\mu \mathrm{m}$. Each fraction was compacted at fixed amplitudes between punches. The second portion was passed through BSS no. 25 and compacted at different amplitudes $(3-5 \mathrm{~cm})$ between punches. Above procedure was repeated using acacia gum (ACG) as the standard binder.

\section{Evaluation of granules}

\section{Bulk density, Tap density, Hausner's ratio and Carr's index}

Granules (149-707 $\mu \mathrm{m}$ ) weighing $20 \mathrm{~g}$ and containing 1.0 to $3.0 \%$ $\mathrm{w} / \mathrm{w}$ MVM was transferred into $50 \mathrm{ml}$ graduated cylinder and tapped at a height of $5 \times 10^{-2} \mathrm{~m}$ from the bench. The volume was noted after three tapings and also at equilibrium (constant volume). Bulk density $\left(D_{b}\right)$ and tap density $\left(D_{t}\right)$ were determined based on the three tapings and at equilibrium. Flow properties and cohesiveness of mucilage granules were determined by Hausner index $\left(D_{t} / D_{b}\right)$ and Compressibility index $\left(1-D_{b} / D_{t}\right) 100$ [18].

\section{Angle of repose}

Granules (149-707 $\mu \mathrm{m}$ ) weighing $20 \mathrm{~g}$ were allowed to flow through a funnel to form a heap that just touched the tip of the funnel. The height of the heap $(h)$ and the diameter of the base (D) were used to calculate the Angle of repose ( $\theta)$ [19].

$$
(\theta)=\tan ^{-1} 2 \mathrm{hD}-1
$$

\section{Strength of granules}

Granules (0.250-0.707 $\mu \mathrm{m})$ weighing $6.5 \mathrm{~g}$ were run for 100 revolutions in a friabilitator and sieved through a 60-mesh screen. The oversize granules were weighed and strength of granules determined [20].

$$
\% \text { strength of granules }=(\text { weight } \text { of granules-oversize }
$$$$
\text { weight/weight of granules) } \times 100
$$

\section{Drug-excipient compatibility}

A portion of the sample weighing $100 \mathrm{mg}$ was mixed with $\mathrm{KBr}$ and compressed into discs by applying pressure of 5 tons for $5 \mathrm{~min}$ in a hydraulic press. The pellet was placed in the light path and the IR spectra of MVM, paracetamol and granules mixture were obtained and compared to check for interaction, shift or loss of functional peaks [13].

\section{Evaluation of tablets}

\section{Crushing strength}

One tablet at time $(n=6)$ was placed in between the jaw of Monsanto hardness tester and force required to diametrically break the tablet was determined.

\section{Friability}

Twenty tablets were rotated 100 times in a Roche friabilator ${ }^{\circledR}$. Tablets were then removed dusted, weighed and friability calculated as percentage weight loss [20].

\section{Disintegration time}

One tablet was placed into each of the six tubes of disintegration apparatus (Model ED-2 Electrolab, Mumbai) and suspended in 900 $\mathrm{ml}$ of $0.1 \mathrm{M} \mathrm{HCl}$ medium at $37 \pm 1{ }^{\circ} \mathrm{C}$. The time taken by each tablet to break into small particles was noted [21].

\section{Dissolution rate}

The Paraceta mol in vitro release profiles were determined in $900 \mathrm{ml}$ phosphate buffer ( $\mathrm{pH} 5.8$ ) at $37 \pm 1^{\circ} \mathrm{C}$ using basket apparatus no. 2 at $50 \mathrm{rpm} .10 \mathrm{ml}$ samples were drawn after $5 \mathrm{~min}$ and subsequently after every $10 \mathrm{~min}$ for $1 \mathrm{~h}$. The samples were filtered, diluted and the absorbance determined at $243 \mathrm{~nm}$. Amount of drawn sample was replaced by equivalent volume of buffer solution [21].

\section{Evaluation of in vitro properties}

Tablet in vitro properties are usually evaluated using variables that include crushing strength (CS), friability ratio (FR) and disintegration time (DT). The in vitro properties evaluated were mechanical strength and drug release. Crushing strength-friability ratio (CS/FR) was used to evaluate mechanical strength of tablets while drug release was measured by CS/FR: DT ratio. Stronger tablets have higher CS/FR ratio while high CS/FR: DT ratio indicates a better balance between mechanical strength and disintegration properties of tablets [22].

\section{Data analysis}

Multivariate analysis including analysis of variance (ANOVA), correlation, regression and t-test were used to test for significant effect of binder concentration, granule size and distance between punches on mechanical and drug release properties of tablets. Graphs were plotted in Microsoft Excel and data analyzed by IBM SPSS. All values were expressed as mean \pm SD. Values of $\mathrm{P}<0.05$ and $\mathrm{P}<0.01$ were considered to be statistically significant.

\section{RESULTS AND DISCUSSION}

\section{Properties of granules}

The decrease in bulk and tap density with increase in the amount of mucilage (table 2), indicated the capability of MVM to enlarge granules and concentrate binding bridges. High values of tap density showed the existence of particle attraction and interlocking property. The registered $\mathrm{CI}(<15 \%)$ and $\mathrm{HI}(<1.25)$ values in all formulations signified that mucilage granules were cohesive, free-flowing, compressible and possessed desirable packing characteristics (table 2). The significant difference in granule flow between $2.5 \%$ and $3 \%$ $\mathrm{w} / \mathrm{w}$ mucilage formulations was due to increase in density and saturation of the binding forces [23]. The angle of repose was less than $30^{\circ}$ within the tested formulations. This illustrated good flow and uniform distribution of bridging forces [19]. Decrease in percentage 
friability and fines with an increase in binder concentration (table 2) signified capability of the mucilage to bind particles and form granules with satisfactory properties. The observed negative correlations $(\mathrm{r}<1)$ with the micrometric properties and mucilage concentration showed that densification, ability to flow and cohesiveness of the granules were dependent on mucilage concentration.

Table 2: Micrometric properties of granules vs. amount of MVM

\begin{tabular}{|c|c|c|c|c|c|c|}
\hline Binder & Bulk density (g/ml) & Tap density (g/ml) & Hausner's index & Compressibility index (\%) & Angle of repose $(\theta)$ & \% Friability \\
\hline 1.0 & $0.665 \pm 0.006$ & $0.770 \pm 0.002$ & $1.160 \pm 0.008$ & $13.70 \pm 0.006$ & $27.32 \pm 1.52$ & $19.42 \pm 0.5$ \\
\hline 1.5 & $0.651 \pm 0.005$ & $0.740 \pm 0.004$ & $1.142 \pm 0.002$ & $12.46 \pm 0.002$ & $27.52 \pm 1.01$ & $18.75 \pm 0.12$ \\
\hline 2.0 & $0.628 \pm 0.003$ & $0.712 \pm 0.004$ & $1.130 \pm 0.002$ & $12.46 \pm 0.002$ & $28.35 \pm 1.08$ & $18.41 \pm 0.5$ \\
\hline 2.5 & $0.620 \pm 0.003$ & $0.690 \pm 0.007$ & $1.123 \pm 0.007$ & $11.79 \pm 0.006$ & $30.19 \pm 0.64$ & $18.13 \pm 0.3$ \\
\hline 3.0 & $0.602 \pm 0.007$ & $0.655 \pm 0.007$ & $1.088 \pm 0.003$ & $10.96 \pm 0.003$ & $29.55 \pm 0.59$ & $17.24 \pm 0.7$ \\
\hline
\end{tabular}

$\mathrm{n}=3$, data presented as mean $\pm \mathrm{SD}$ and $\mathrm{p}<0.01$

\section{Drug-mucilage compatibility}

$M$. verticillata mucilage was found to be compatible with paracetamol because all individual characteristic and functional vibrational peaks associated with the active principle were observed in the FTIR spectra of granules mixture (fig. 1). The observable functional peaks include 0 -
$\mathrm{H}, \mathrm{N}-\mathrm{H}, \mathrm{C}=\mathrm{O}$ and $\mathrm{C}-\mathrm{N}$ stretching bands at 3326.98, 3413.77, 1654.81 and $1259.43 \mathrm{~cm}^{-1}$ respectively. Decrease in IR absorption intensity of hydroxyl functional group of paracetamol in the granule mixture illustrates the possibility of formation of hydrogen bonds [13, 24]. Absence of peak shifting and retention of functional peaks indicated that there was no chemical interaction in the mixture.

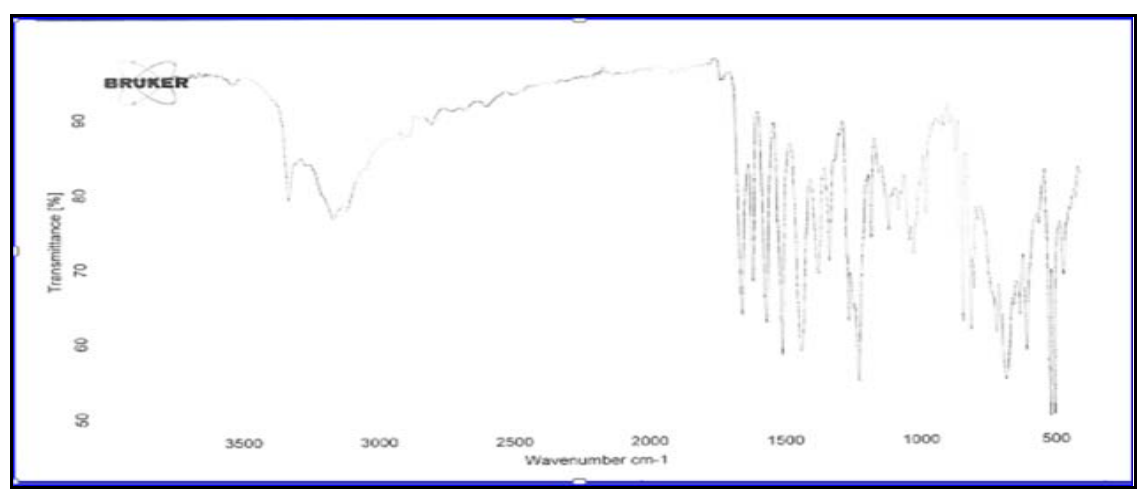

Fig. 1: FTIR spectrum of granule mixture

\section{Mechanical strength of tablets}

Effect of the amount of MVM and ACG on the mechanical strength of tablets are presented in table 3 below. Friability was observed to decrease with increase in the concentration of binder. During the test, none of the tablets cracked, peeled or smashed. This indicated the potential of MVM and ACG to enhance formation of adhesive bridges which resist abrasion, shock and capping tendencies, common with substances which undergoing fragmentation [25].

The significant correlation $(\mathrm{r}>1, \mathrm{P}<0.01)$ between the amount of mucilage and crushing strength, signifies ability of MVM to form a thick mucilaginous film which contributes to tablet strength [26]. Increase in mucilage concentration by $1.0 \% \mathrm{w} / \mathrm{w}$ had a significant effect $(p>0.05)$ on the hardness of tablets. This indicated that the binding potential of MVM was concentration-dependent.

Mechanical strength of the tablets obtained from mucilage formulation was found to be superior to those of acacia gum at $2-3 \%$ $\mathrm{w} / \mathrm{w}$ concentration as depicted by high CS/FR ratio [22]. This was supported by high regression coefficient of 1.78 in MVM as compared to 1.43 of acacia tablets. Tablets containing $1 \% \mathrm{w} / \mathrm{w}$ mucilage were weaker than corresponding acacia tablets because of high bulk density which reduces space for deformation while ACG increases packing per unit space [27].

Table 3: Mechanical strength of tablets containing different amount of binders

\begin{tabular}{llllll}
\hline Binder concentration (\% w/w) & \multicolumn{2}{c}{ Crushing strength (kg/cm $\mathbf{c}^{\mathbf{2}}$ ) } & \multicolumn{2}{c}{ Friability (\%) } & \multicolumn{2}{c}{ Crushing strength-friability ratio (CS/FR) } \\
\cline { 2 - 6 } & MVM & ACG & MVM & ACG & MVM \\
\hline $\mathbf{1 . 0}$ & $3.54 \pm 0.27$ & $3.58 \pm 0.34$ & $0.86 \pm 0.01$ & $0.66 \pm 0.04$ & $4.12 \pm 0.30$ \\
$\mathbf{1 . 5}$ & $5.07 \pm 0.14$ & $4.18 \pm 0.16$ & $0.55 \pm 0.01$ & $0.54 \pm 0.02$ & $9.16 \pm 0.14$ \\
$\mathbf{2 . 0}$ & $6.15 \pm 0.06$ & $5.12 \pm 0.04$ & $0.51 \pm 0.02$ & $0.435 \pm 0.03$ & $12.07 \pm 0.42$ \\
$\mathbf{2 . 5}$ & $6.78 \pm 0.25$ & $5.94 \pm 0.33$ & $0.38 \pm 0.01$ & $0.42 \pm 0.02$ & $17.85 \pm 0.20$ \\
$\mathbf{3 . 0}$ & $7.12 \pm 0.21$ & $6.26 \pm 0.25$ & $0.35 \pm 0.03$ & $0.33 \pm 0.01$ & $17.0 \pm 0.25$ \\
\hline
\end{tabular}

$\mathrm{n}=3$, data presented as mean $\pm \pm S D, p<0.05$ ).

Fig. 2 below shows the effect of increasing distance between punches on mechanical properties of tablets. The significant correlation $(r>1$, $\mathrm{p}<0.01$ ) between CSFR and distance between punches shows that increasing distance between punches results in tablets with high mechanical strength. This could be due to gas displacement and closer particle-particle interaction leading to the formation of strong bonds [11]. However, increasing distance between punches did not have any significant $\left(\mathrm{F}_{(4,10)}=3.307, \mathrm{P}=0.123\right)$ effect on tablet hardness. 


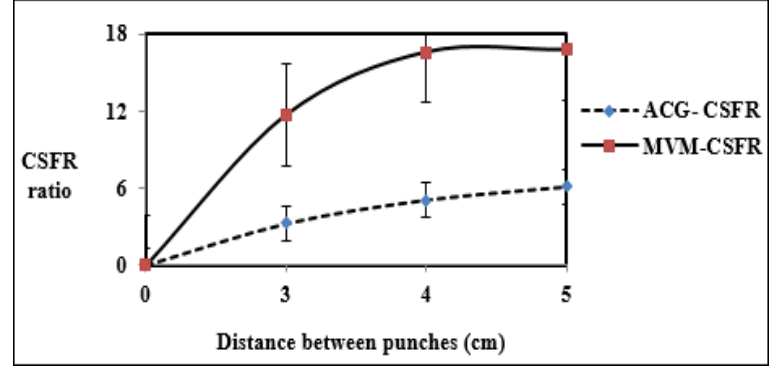

Fig. 2: Effect of distance between punches on the mechanical strength of tablets containing $2.0 \% \mathrm{w} / \mathrm{w} \mathrm{M}$. verticillata mucilage and acacia gum as a binder, mean $\pm S D, n=3, p<0.01$. ACG-CSFR and MVM-CSFR is the crushing strength-friability ratio of tablets containing acacia gum and $M$. verticillata mucilage as tablet binder, respectively

Fig. 3a below shows that crushing strength decreased significantly $\left(\mathrm{F}_{(4,}\right.$ 10) $=405.475, \mathrm{P}<0.05$ ) with an increase in granule size. Tablets obtained from the initial granule mixture $(149-707 \mu \mathrm{m})$ were stronger than those obtained from 500-707 $\mu \mathrm{m}$. This was due to wider particle size distribution, better packing rearrangement and extra adhesive bridges by fines in void spaces. Small sized granules $(149-250 \mu \mathrm{m})$ on compression yielded stronger tablets as they packed well and had a larger surface area which contributed to the formation of strong interparticulate bonding. Larger sized granules $(500-707 \mu \mathrm{m})$ have smaller surface area and high void spaces resulting information weak interparticulate bonds in compressed tablets [28]. Lack of fragmentation of the large mucilage granules resulted in to weaker tablets [8]. Analysis of the result shows the insignificant difference $(p>0.01)$ between mechanical strength of MVM and ACG tablets obtained from compressing granules of different size (fig. $3 \mathrm{~b}$ ).

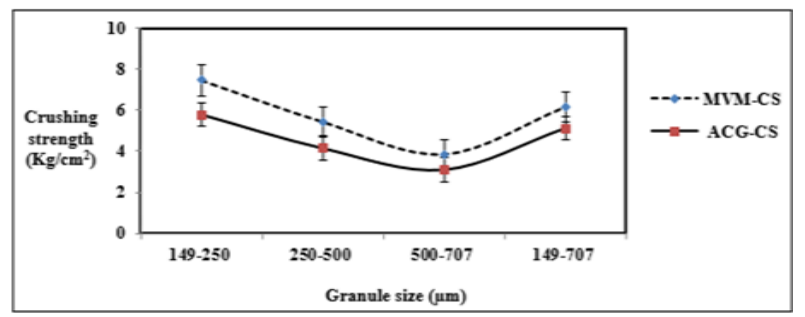

Fig. 3a: Effect of granule size on crushing strength of tablets, mean $\pm S D, n=3, p<0.05$ ACG-CS and MVM-CS is crushing strength of tablets containing acacia gum and $M$. verticillata mucilage, respectively

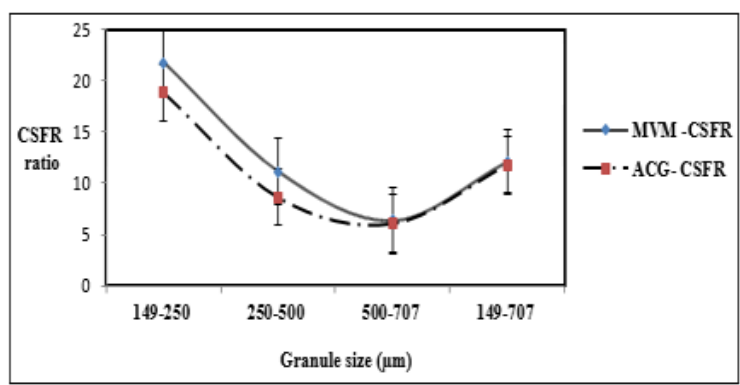

Fig. 3b: Effect of granule size on the mechanical strength of tablets, mean $\pm S D, n=3, p<0.01$ ACG-CSFR and MVM-CSFR is the mechanical strength-friability ratio of tablets containing acacia gum and M. verticillata mucilage, respectively

Results in table 3, fig. 2 and 3 above, showed that mechanical properties of mucilage tablets in all tested variables; concentration, granule size and distance between punches were high and significantly different from those of acacia tablets $\left(t_{26}=\right.$ 7.963, $\mathrm{p}<0.05$ ). The following model equation was used to indicate that tablet hardness increased significantly with a decrease in granule size, increase in the concentration of mucilage and increase in distance between punches.

$$
Y_{1}=6.03+1.79 X_{1}-1.76 X_{2}+0.83 X_{3}
$$

Where $\mathrm{Y}_{1}$ is hardness in $\mathrm{kg} / \mathrm{cm}^{2}, \mathrm{X}_{1}$ is mucilage concentration $(\%$ $\mathrm{w} / \mathrm{w}), \mathrm{X}_{2}$ is granule size in $\mu \mathrm{m}$ and $\mathrm{X}_{3}$ is the distance between punches in $\mathrm{cm}$. The negative coefficient $(-1.760)$ signified that crushing strength decreased significantly $(\mathrm{p}<0.05)$ with an increase in granule size. The high correlation coefficient (1.79) indicated that binding potential of MVM was concentration-dependent. A low coefficient of $\mathrm{X}_{3}$ implied the insignificant effect of distance between punches.

\section{Disintegration time}

Table 4 below shows the effect of increasing concentration of binder on the time of disintegration. The significant correlation $(\mathrm{p}<0.05)$ between the concentration of MVM and disintegration time was due to the formation of a mucilaginous viscous film which hindered penetration of water thus preventing disintegration [11]. This effect was more pronounced in tablets containing $3 \% \mathrm{w} / \mathrm{w}$ mucilage that disintegrated after 16 min which is above the phermocopial limit of $\leq 15 \mathrm{~min}$ [29]. This observation showed that mucilage at high concentration has strong binding properties which may hinder disintegration. Regression analysis showed that hardness of tablets had less influence on disintegration time than the amount of binder.

Table 4: Disintegration time for tablets containing different amount of MVM and ACG as tablet binder

\begin{tabular}{llll}
\hline Binder concentration (\% & \multicolumn{2}{l}{ Disintegration time (min) } & CSFR: DT \\
\cline { 2 - 4 } w/w) & MVM & ACG & MVM \\
\hline 1.0 & $7.13 \pm 0.51$ & $3.35 \pm 0.13$ & $0.58 \pm .006$ \\
1.5 & $9.23 \pm 0.28$ & $4.52 \pm 0.06$ & $0.94 \pm 0.03$ \\
2.0 & $12.17 \pm 0.53$ & $5.71 \pm 0.57$ & $1.0 \pm 0.04$ \\
2.5 & $14.80 \pm 0.48$ & $7.15 \pm 0.13$ & $1.21 \pm 0.05$ \\
3.0 & $16.67 \pm 0.59$ & $7.35 \pm 0.20$ & $0.97 \pm 0.01$ \\
\hline
\end{tabular}

$\mathrm{n}=3$, data presented as mean $\pm \mathrm{SD}, \mathrm{p}<0.05$ ).

Fig. 4a below shows the effect of granule size on disintegration time of tablets. The negative correlation $(r<1, p<0.01)$ between disintegration time and tablets obtained by compressing granules of different sizes suggested that disintegration time decreased with increase in granule size. Large granules in the size range 500-700 $\mu \mathrm{m}$ disintegrated faster than small sized granules. This could be explained in terms of porosity. Large granules form strong pores which do not collapse during compression while small sized granules of less than $250 \mu \mathrm{m}$ form collapsible pores. Small pores reduce penetration and hence increase disintegration time. Earlier studies attributed disintegration to swelling and creation of other active disintegration mechanisms [26]. The poor disintegration of tablets obtained from the initial granule mixture $(149-707 \mu \mathrm{m})$ may have been due to particle size distribution, hindered penetration and strong binding contributed by fines. However, 
granule size was found to have no significant effect on drug release properties as shown by CSFR/DT values (fig. $4 \mathrm{~b}$ ).

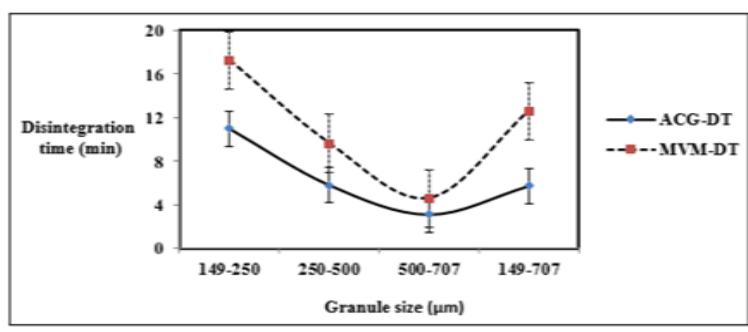

Fig. 4a: Effect of granule size on disintegration time of tablets, mean $\pm S D, n=3, p<0.01$ ACG-DT disintegration time of tablets containing acacia gum and $M$. verticillata mucilage, respectively

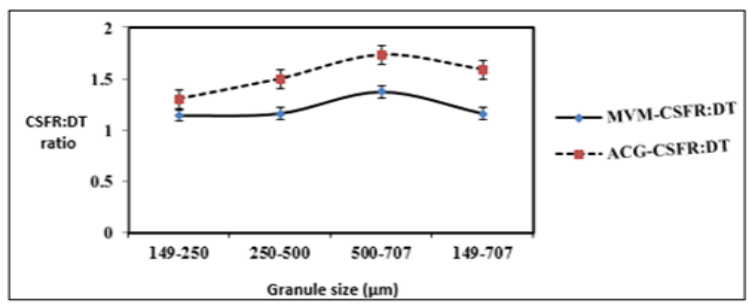

Fig. 4b: Effect of granule size on drug release properties of tablets, mean $\pm S D, n=3, p<0.01$ ACG-CSFR-DT is the crushing strength-friability, disintegration time ratio of tablets containing acacia gum and M. verticillata mucilage, respectively

Fig. 5 below shows the insignificant correlation $(r>1, p>0.01$ ) between the effects of increasing distance between punches on disintegration time. Wider distance between punches brings particles closer to each other resulting in a reduction in tablet porosity and hence increase in disintegration time.

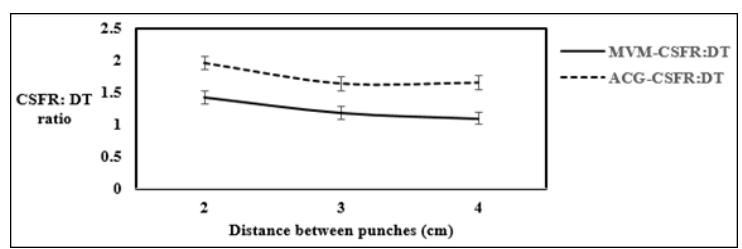

Fig. 5: Effect of pressure on drug release properties of tablets containing $M$. verticillata mucilage and acacia gum as tablet binder, mean $\pm S D, n=3, p<0.01$. AGM-CSFR: DT and MVM-CSFR: DT is the Crushing strength-friability, disintegration time ratio of tablets containing $2.0 \% \mathrm{w} / \mathrm{w}$ of acacia gum and $M$. verticillata mucilage as tablet binder respectively

Results in table 4 , fig. 4 and 5 above shows that mucilage tablets were less superior and significantly different at all tested variables from those of acacia tablets $\left(t t_{14}=-39.925, \mathrm{p}<0.05\right)$. This was revealed by low values of CSFR: DT. The negative coefficient indicated that mucilage retarded disintegration time more than acacia gum. Decreasing granule size while increasing MVM concentration and distance between punches hindered disintegration thus increasing tablet disintegration time as shown by the following model equation.

$$
Y_{2}=13.18+4.77 X_{1}-3.04 X_{2}+2.29 X_{3}
$$

Where $Y_{2}$ is disintegration time in minutes, $X_{1}$ is $s$ concentration of mucilage $(\% \mathrm{w} / \mathrm{w}), X_{2}$ is granule size in microns and $X_{3}$ is the distance between punches. High coefficient of concentration (4.77) indicates that it has more influence on disintegration time than other tested variables. The peak CS/FR: DT values for mucilage tablets was recorded at $2.5 \%$ $\mathrm{w} / \mathrm{w}, 149-707 \mu \mathrm{m}$ granule size and when compressed at low pressure (table 4, fig. 4 and 5). This observation are indicative of the optimum conditions for the formulation of mucilage tablets.

\section{DISSOLUTION}

Fig. 6 illustrates the cumulative amount of drug release against time for tablets containing 2.0 and $3.0 \% \mathrm{w} / \mathrm{w}$ MVM and ACG as a binder. The positive correlation $(r>0.947)$ between the amount of drug released and time indicated a constant drug release. The gradient of the curves with a dipping slope at the initial stage was an indication of the ability of tablets to boost and maintain constant drug concentration in vivo. High dissolution rate of ACG tablets was through the enhancement of drug solubility [28]. Low release rate of mucilage tablets was due to hydration which leads to the formation of the mucilaginous and sticky film. The viscosity of the film and diffusional path length determines the release rate [12]. Cumulative amount of $68.94 \%$ for tablets containing $3.0 \%$ $\mathrm{w} / \mathrm{w}$ mucilage at the end of $30 \mathrm{~min}$ was below the Pharmacopeial limit ( $>80 \%$ after $30 \mathrm{~min}$ ) and is an indication of tablet with slower release rates.

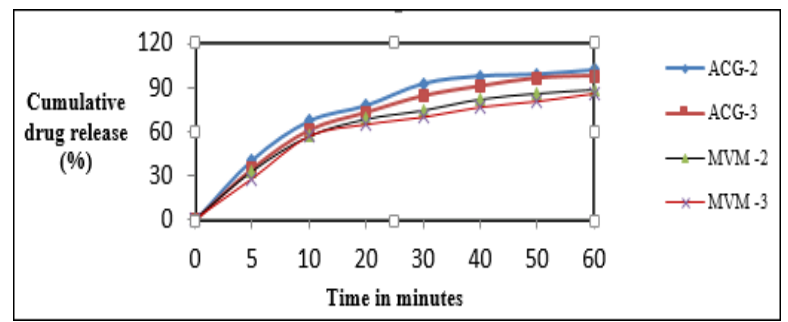

Fig. 6: Cumulative percentage of drug release Vs. time of tablets containing 2.0 and $3.0 \% \mathrm{w} / \mathrm{w}$ M. verticillata mucilage and acacia gum as tablet binder, $n=3$ and $\mathbf{p}<0.01$, ACG-2 and ACG-3 tablet containing $\mathrm{g} 2.0$ and $3.0 \% \mathrm{w} / \mathrm{w}$ acacia gum as tablet binder, MVM-2 and MVM-3 tablet containing g 2.0 and $3.0 \%$ $\mathrm{w} / \mathrm{w}$ M. verticillata mucilage as tablet binder

\section{CONCLUSION}

The in vitro properties of mucilage tablets varied in all the tested variables. M. verticillata mucilage is compatible with paracetamol and has the capability to improve granule flow. Small sized granules when compressed at high-pressure yields tablets with high mechanical strength and poor drug release properties. Compression pressure and granule size were found to have no significant effect on drug release properties of MVM tablets. Granules in the size range of $149-707 \mu \mathrm{m}$ containing $2.0 \% \mathrm{w} / \mathrm{w}$ mucilage yield tablets with good mechanical strength and drug release rate properties comparable with those of acacia gum. This study has shown that $M$. verticillata mucilage at a higher concentration can be exploited as a binder in the formulation of slow release and mucoadhesive tablets.

\section{ACKNOWLEDGEMENT}

The authors would like to acknowledge the financial support for the research work from the National Council for Science, Technology and Innovation (NACOSTI-Kenya) through PC Korir. We thank Mr. Patrick Mutiso of University of Nairobi Herbarium for verification and identification of plant samples.

\section{AUTHORS CONTRIBUTIONS}

The conception and formulation of the research methodology were done by the first author who was also responsible for execution of the experiments and drafting of the manuscript. The four co-authors were jointly involved in the design of the work, supervision, conducting a literature search and writing of the manuscript.

\section{CONFLICT OF INTERESTS}

The authors declare that they have no conflict of interest. 


\section{REFERENCES}

1. Rubinstein MH, Aulton ME. editor. Tablets. In: Pharmaceutics, the science of dosage form design. New York: Churchill Livingstone; 2000.

2. David B, Troy, Paul B. Remington: the science and practice of pharmacy. USA: Lippincott Williams and Wilkins; 2006.

3. Oyi AR, Allagh TS, Olayemi OJ. Comparative binding effects of wheat, rice and maize starches in chloroquine phosphate tablet formulations. Res J Appl Sci Eng Technol 2009;1:131-6.

4. Ibezim EC, Ofoefule SI, Omeje EO, Onyishi VI, Odoh UE. The role of ginger as a binder in acetaminophen tablets. Sci Res Essays 2008;3:46-50.

5. Narayan BG, Giriraj K. Evaluation of Buchanania cochinchinesis gum as a binder in formulation development of paracetamol tablets. Int J Pharm Pharm Sci 2013;5:283-9.

6. Johansson B, Nicklasson F, Alderborn G. Effect of pellet size on the degree of deformation and densification during compression and on compatibility of microcrystalline cellulose pellets. Int J Pharm 1998;163:35-48.

7. Zuurman K, Riepma KA, Bolhuis GK, Vromans H, Lerk CF. The relationship between bulk density and compatibility of lactose granulations. Int J Pharm 1994;1-9. Doi:0.1016/0378517390033-7.

8. Santl M, Ilija I, Vrecer F, Baumgartner S. Compressibility and compatibility study of real tableting mixtures: the effect of granule particle size. Acta Pharm 2012;62:325-40.

9. Iman MH, Adil MAS, Suaad E, Wala AM, A Salman, Wala AMAS. The effect of particle size on the compressibility of cinnamon granules. J Appl Ind Sci 2015;3:150-3.

10. Chaudhary A, Kulkarni GT, Awasthi R, Kumar P. Investigation on binding properties of Grewi asiatica mucilage in tablet formulations. Marmara Pharm J 2016;20:353-67.

11. Olutayo AA, Mbang NF, Michael AO. Effect of compression pressure on mechanical and release properties of tramadol matrix tablets. Curr Issues Pharm Med Sci 2015;28:120-5.

12. Nanjwade BK, Ali MS, Nanjwade VK, Manvi FV. Effect of pressure on dissolution and solid state characterization of cefuroxime axetil. J Anal Bioana Tech 2010;1:2-6.

13. Patel NC, Pandya TV, Shah NS, Mahajan AN. Isolation of mucilage from Cydonia vulgaris pers. Seeds:and its evaluatio $\mathrm{n}$ as a tablet binder. Int J Pharm Pharm Sci 2011;3:351-5.
14. Bodas KS, Potnis VV, Patel MJ, Satpute KL, Sheth NS Preliminary evaluation of binding properties of Randia dumetorum fruit mucilage. Int J Pharm Technol 2010;2:440-55.

15. Rishabha M, Pranati S, Kulkarni GT. Application of mucilages in drug delivery-a review. Adv Biol Res 2011;5:1-7.

16. Laurence JD, Malva verticillata $\mathrm{L}$, the Integrated Taxonomic Information System, ITIS, 21841 Taxonomic Serial No. 21841; 2007-2010.

17. Bruneton J. Pharmacognosy: phytochemistry medicinal plants. Edition 2. Lavoisier Publishing, New York; 1999. p. 80-91.

18. Staniforth J, Aulton ME. editor. Powder flow, Pharmaceutics, The Science of Dosage Form Design. Edinburgh London: Churchill Livingstone; 2002.

19. Geldart D, Abdullah EC, Hassanpour A, Nwoke LC, Wouters I. Characterization of powder flowability using the measurement of the angle of repose. China Particuol 2006;4:104-7.

20. The Japanese Pharmacopoeia. $4^{\text {th }}$ ed. Part I; XIV, Tablet friability test; 2001. p. 1326-7.

21. Indian Pharmacopoeia. Vol. II. Ministry of health and Family Welfare, Govt. of India, Controller of Publications, New Delhi; 1985. p. A-73-122.

22. Autamashih M, Isah AB, Allagh TS, Ibrahim MA. Use of anhydrous calcium phosphate and selected binders in the tablet formulation of a deliquescent crude plant extract: Vernonia galamensis (Asteraceae). J Appl Pharm Sci 2011;1:118-22.

23. Chime SA, Brown SA, Ugwu CE, Agubata CO, Obidike TC, Onunkwo GC. Effect of binder type and concentration on the in vitro properties of Alstonia boonei tablets. Int J Pharm Sci Rev Res 2012;16:5-9.

24. Mukherjee B, Samanta A, Chandra SD. Gum Odina-A new tablet binder. Trends Appl Sci Res 2006;1:309-16.

25. Femi Oyewo MN, Aremu OI, Kehinde OJ. Evaluation of Beilschmiedia seed gum as a tablet binder. East Central Afr J Pharm Sci 2009;12:15-21.

26. Ogunjimi AT, Alebiowu 0 . Neem gum as a binder in a formulated paracetamol tablet with reference to acacia gum BP. AAPS PharmSciTech 2014;5:500-10.

27. Eichie FE, Kudehinbu AO. Effect of particle size of granules on some mechanical properties of paracetamol tablets. Afr J Biotechnol 2009;8:5913-6.

28. Umeh ON, Ekeugo UE, Ofoefule SI. Effect of particle size and some formulation components on the mechanical properties and in vitro release profile of metronidazole from compressed tablets. Am J Chem Appl 2015;2:28-34.

29. The United States Pharmacopeial Convention; 2012. XXV. 616. 